\title{
EFEKTIFITAS UPRIGHT POSITION DAN SIM POSITION TERHADAP LAMANYA PERSALINAN KALA I FASE AKTIF PADA PRIMIGRAVIDA
}

\author{
EFFECTIVENESS OF UPRIGHT POSITION AND SIM POSITION \\ ON THE TIME OF LABOR IN THE I ACTIVE PHASE ON PRIMIGRAVIDA
}

\author{
Rinda Lamdayani ${ }^{1}$, Rini Anggeriani ${ }^{2}$, Madila Tasya ${ }^{3}$ \\ Sekolah Tinggi Ilmu Kesehatan Abdurahman Palembang ${ }^{123}$ \\ email: rindalamdayani5@gmail.com¹, anggeriani_r@ymail.com ${ }^{2}$,dilathasya@gmail.com ${ }^{3}$
}

\begin{abstract}
ABSTRAK
Pada proses persalinan bisa terjadi persalinan menjadi lama dan sulit yang mengakibatkan komplikasi pada ibu dan bayinya. Penatalaksanaan persalinan yang lama bergantung kepada penyebab dan bisa dilakukan dengan merubah posisi ibu bersalin.Posisi yang nyaman selama persalinan sangat diperlukan bagi pasien. Selain mengurangi ketegangan dan rasa nyeri, posisi tertentu justru akan membantu proses penurunan kepala janin sehingga persalinan dapat berjalan lebih cepat. Penelitian ini bertujuan untuk menganalisis efektifitas posisi Upright Position dan SIM Position terhadap lamanya persalinan Kala I Fase Aktif pada Primigravida.Dengan menggunakan metode studi literature maka dilakukan analisis terhadap hasil penelusuran jurnal (e-jurnal) dan artikel dengan tinjauan teori yang ada (e-book). Penelitian ini mengungkapkan bahwa efektifitas pemberian posisi antara lainUpright position dan SIM Position. Hasil dari penelitian ini menunjukkan bahwa Upright position lebih efektif digunakan untuk ibu bersalin.Tenaga kesehatan, khususnya bidan dapat memberikan posisi yang nyaman bagi ibu bersalin.
\end{abstract}

Kata kunci : Persalinan, Upright position, SIM position

\begin{abstract}
During childbirth, there is a long and difficult labor that causes complications to the mother and her baby. Long delivery management depends on the cause and can be done by changing the position of maternity mothers comfortable position during labor is necessary for the patient. In addition to reducing tension and pain, certain positions will precisely help the process of decreasing fetal head so that childbirth can run faster. This research aims to analyze the effectiveness of the position of Upright Position and SIM Position on the length of labor during the period of the Primigravida. By using the method of literature study, analysis of journal search results (e-journals) and articles with existing theory review (e-book). The study revealed that the effectiveness of the position-giving between the Upright position and the SIM Position. The results of this study show that Upright position is more effectively used for maternity mothers. Health professionals, especially midwives, can provide a comfortable position for maternity mothers.
\end{abstract}

Keywords: Childbirth, Upright position, SIM positio 


\section{PENDAHULUAN}

Persalinan merupakan proses alamiah yang dialami seorang wanita pada akhir proses kehamilannya. Fisiologi ibu dalam persalinan akan terjadi perubahan dan dipengaruhi oleh banyak faktor. Asuhan kebidanan pada kala I sangat diperlukan bagi ibu dalam melalui proses awal persalinan ${ }^{1}$.

Persalinan normal adalah proses pengeluaran janin yang terjadi pada kehamilan cukup bulan (37-42 minggu), lahir spontan dengan presentasi belakang kepala yang berlangsung selama 18 jam, tanpa komplikasi baik pada ibu maupun pada janin $^{2}$.

Sejumlah perubahan fisiologis terjadi pada ibu selama persalinan. Sangat penting bagi bidan untuk memahami perubahan-perubahan ini agar dapat membedakan tanda-tanda dan gejala persalinan normal dan abnormal ${ }^{3}$.

Aspek-aspek asuhan yang terbukti memenggaruhi perasaan persalinan dan kepuasan pengalaman persalinan meliputi komunikasi pemberian informasi, penatalaksanaan nyeri, tempat melahirkan, dan dukungan social dari keluarga/pasangan, serta dukungan dari pemberi asuhan.Pengontrolan dan penatalaksanaan nyeri persalinan adalah salah satu aspek asuhan yang dapat mempengaruhi persepsi wanita terhadap kelahiran dan rasa kepuasan setelah melahirkan. Penelitian yang dilakukan Morgan menunjukkan bahwa sejumlah wanita yang tidak memperoleh agen penghilang rasa nyeri dalam persalinan menunjukkan rasa nyeri yang tinggi, sebaliknya wanita yang memperoleh pereda nyeri total seperti penggunaan anastesi apidural menunjukkan tingkat kepuasan yang lebih rendah.

Rasa nyeri yang dirasakan tergantung pada banyak fakktor psikososial, derajat kualitas nyeri yang dirasakan ditentukan oleh pengalaman sebelumnya dan seberapa baik pengalaman tersebut diingat.Presepsi nyeri juga tergantung pada pemahaman tentang penyebab rasa nyeri dan kemampuan untuk memikul konsekuensinya ${ }^{3}$.

Menurut Sulistyawati (2010), Saat memberikan asuhan kepada ibu yang sedang bersalin, penolong harus sselalu waspada terhadap masalah atau penyulit yang mungkin terjadi. Selama anamnesis dan pemeriksaan fisik, tetap waspada terhadap timbulnya tanda bahaya kala I dan lakukan tindakan segera. Lakukan langkah dan tindakan yang sesuai untuk memastikan proses persalinan yang aman bagi ibu dan keselamatan bagi bayi yang dilahirkan ${ }^{4}$.

Pada saat proses persalinan bisa terjadi persalinan menjadi lama dan sulit yang mengakibatkan komplikasi pada ibu dan bayinya. Penatalaksanaan persalinan yang lama bergantung kepada penyebab dan bisa dilakukan dengan merubah posisi ibu bersalin, pemberian induksi persalinan, kelahiran forcep, ekstrasi vakum, dan kelahiran seksio cesaria ${ }^{5}$.

Berbagai upaya fisiologis dilakukan penolong persalinan professional agar ibu, terutama primigravida yang mengalami persalinan kala I fase aktif lebih dari 6 jam. Salah satu upaya dalam melayani ibu dalam proses persalinan adalah dengan mengkondisikan dan mengupayakan seperti upright position yang mendukung persalinan agar dapat berjalan secara fisiologis. Hal ini juga merupakan salah satu metode yang sangat membantu merespon rasa sakit dengan cara aktif dan 
mengurangi lama persalinan kala I fase aktif $^{6}$.

Menurut penelitian Syaflindawati dkk (2015) tentang "Pengaruh Upright Position Terhadap Lamanya Kala I Fase Aktif pada Primipara" memperlihatkan rerata dan standar deviasi pada posisi berbaring 263,68 $\pm 39,47$ menit, sedanglam pada posisi upright position adalah 161,05 \pm 40,26 menit ${ }^{7}$.Menurut penelitian Titi Astuti dkk, (2013) tentang "Pengaruh Posisi Tegak (Upright) Terhadap Rasa Nyeri Dan Lamanya Kala I Persalinan Ibu Primipara" didapatkan hasil kemajuan persalinan lama persalinan kala I pada ibu primipara dengan waktu terpendek 5 jam dan terpanjang 12 jam. Sedangkan ibu primipara kelompok kontrol didapatkan waktu terpendek 10 jam dan terpanjang 20 jam.

Kala I adalah kala pembukaan yang berlangsung antara pembukaan $0-10 \mathrm{~cm}$ (pembukaan lengkap). Proses ini terbagi menjadi 2 fase, yaitu fase laten ( 8 jam) dimana serviks membuka sampai $3 \mathrm{~cm}$ dan fase aktif (7 jam) dimana serviks membuka dari 3-10 $\mathrm{cm}^{4}$.

Posisi yang nyaman selama persalinan sangat diperlukan bagi pasien. Selain mengurangi ketegangan dan rasa nyeri, posisi tertentu justru akan membantu proses penurunan kepala janin sehinggapersalinan dapat berjalan lebih cepat (selama tidak ada kontra indikasi dari keadaan pasien). Beberapa posisi yang dapat diambil antara lain rekumben lateral (miring), lutut-dada, tangan-lutut, duduk, berdiri, beralan, dan jongkok ${ }^{4}$.

Posisi tegak pada proses persalinan kala I diasosiasikan dapat memberikan keuntungan pada ibu maupun bayi, karena dapat memberikan relaksasi dan memberikan sedikit tekanan pada sirkulasi darah sehingga memberikan suplai oksigen pada bayi, selain itu posisi tegak juga dapat mempercepat penurunan kepala karena adanya gaya gravitasi bumi sehingga memperpendek waktu persalinan kala I. Wanita yang memilih (upright position) posisi tegak, berjalan atau jongkok merasakan kepuasan dan kenyamanan saat proses persalinan ${ }^{8}$.

Posisi tegak pada persalinan kala I fase aktif dapat memperpendek waktu persalinan lebih kurang 1 jam dan dapat memberikan relaksasi pada pembuluh darah dan juga dapat memberikan percepatan penurunan kepala karena adanya gaya gravitasi bumi sehingga dapat memperpendek kala I. Posisi tegak juga dapat meningkatkan kontrol diri terhadap rasa nyeri. Ada sedikit pengurangan tekanan pada sirkulasi darah sehingga memberikan suplai oksigen ke bayi lebih banyak yang sangat baik untuk ibu maupun bayi ${ }^{6}$.

Menurut Norflok dkk, (2006) selama proses persalinan ibu menggunakan posisi Upright, proses persalinan waktunya lebih pendek, kontraksi uterus lebih terpantau. Ini membuktikan bahwa posisi Uprightefektif membantu mempercepat lamanya kala I persalinan pada ibu primipara. Pada posisi tegak (Upright) dibanding supine (telentang) kontraksi uterus lebih kuat, membantu janin bergerak turun ke dalam rongga panggul karena didorong gaya gravitasi bumi. Kontraksi yang efektif adalah penting untuk dilatasi serviks dan penurunan bagian terendah janin, walaupun ada banyak aturan penting dalam membantu mengurangi distocia ${ }^{8}$.

Upright position selama persalinan kala I fase aktif memberikan keuntungan yang lebih dibandingkan posisi lainnya termasuk posisi ibu yang berbaring di tempat tidur 
karena posisi berbaring dapat menekan vena cava sehingga dapat menurunkan aliran darah ke plasenta yang menyebabkan janin hipoksia dan menekan diafragma yang membuat ibu sulit untuk bernafas ${ }^{9}$.

Menurut Asrinah (2010), Posisi berdiri berpengaruh terhadap kemajuan persalinan karena dengan adanya gaya gravitasi dapat membantu penurunan bagian terendah janin, memperbesar ukuran panggul menambah $28 \%$ ruang outletnya. Sedangkan pengaruh posisi berdiri pada kala I yaitu dengan adanya gaya gravitasi dapat memperluas pintu atas panggul sehingga membantu penurunan bagian terendah janin turun lebih cepat ${ }^{10}$.

Hasil penelitian ini didukung oleh pendapat Brenda (2006) yang mengatakan perubahan posisi selama proses persalinan bertujuan untuk meningkatkan kenyamanan, menurunkan nyeri, dan membantu kemajuan persalinan direkomendasikan dengan posisi handsknees, berjalan, berdiri, dan berbaring miring, duduk di bola melahirkan. Ibu secara kontinu dapat melakukan perubahan posisi selama proses persalinan dengan baik ${ }^{11}$.

Menurut Lowe (1996) posisi upright dapat mengurangi nyeri selama persalinan.Dari beberapa penemuan ambulasi dengan ritme spesifik dapat meningkatkan toleransi untuk nyeri persalinan saat kontraksi uterus.Perubahan posisi dapat mengurangi nyeri, memperlancar aliran darah ke uterus, kontraksi uterus, penurunan janin, dan kontrol personal (Shermer dkk, 1997).Posisi ibu selama persalinan dan posisi janin di uterus mempengaruhi kenyamanan ibu.Posisi tegak (upright) yaitu berdiri, berjalan, duduk, jongkok pada persalinan kala I dapat menurunkan nyeri bagian belakang (low back pain) dibandingan posisi supine $^{12}$.

Menurut Bobak (2009), mengatakan bahwa posisi dalam persalinan dapat mempengaruhi lamanya proses persalinan berlangsung. Ibu yang banyak bergerak dan dibiarkan memilih posisi yang diingini akan mengalami proses persalinan yang singkat dan rasa nyeri yang berkurang, oleh karena itu, ibu bersalin hendaknya diberi kebebasan memilih posisi yang dirasakan paling nyaman untuk ibu, kecuali jika ada kontra indikasi ${ }^{5}$.

Menurut Wigand dkk (2012), mendapatkan bahwa posisi tegak pada persalinan kala I fase aktif dapat memperpendek waktu persalinan lebih kurang 1 jam dan dapat memberikan relaksasi pada pembuluh darah dan juga dapat memberikan percepatan penurunan kepala karena adanya gaya gravitasi bumi sehingga dapat memperpendek kala I. Posisi tegak juga dapat meningkatkan kontrol diri terhadap rasa nyeri. Ada sedikit pengurangan tekanan pada sirkulasi darah sehingga memberikan suplai oksigen ke bayi lebih banyak yang sangat baik untuk ibu maupun bayi ${ }^{6}$.

Menurut Sherwood (2012) mengemukakan bahwa gaya gravitasi dapat mempermudah penurunan kemajuan persalinan karena janin akan berada pada posisi yang lebih baik untuk berjalan kearah panggul ibu. Gerakan posisi berdiri dapat membantu mempengaruhi frekuensi, lamanya dan efisiensi dari kontraksi yang menyebabkan panggul terbuka lebih lebar dan memberikan ruang pada janin untuk segera keluar ${ }^{9}$.

Cara melakukan posisi berdiri ada 2 cara yaitu ibu berdiri dengan bersandar ke 
tempat tidur, dan ibu bersandar pada pasangan. Hendaknya posisi berdiri dilakukan selama 15-30 menit karena posisi ini dapat menambah dimensi PAP (Simkin, 2005). Dengan posisi berdiri kemajuan persalinan bisa berlangsung secara cepat yaitu kala I (Primigravida) berlangsung 1 jam untuk pembukaan $\geq 1$ $\mathrm{cm}$. Menurut penelitian, waktu persalinan juga bisa lebih cepat jika ibu berdiri atau berjalan. Jika saat berdiri atau berjalanjalan ibu mengalami kontraksi, ibu bisa bersandar ke tubuh suami ibu atau memeluknya.Selagi melakukan posisi ini ibu bisa meminta pasangannya untuk memijat punggung ibu lembut ${ }^{10}$.

Menurut Simkin dkk (2004), Studi ilmiah tentang dampak posisi tegak (Upright) dengan posisi supine terhadap rasa nyeri dan kemajuan persalinan didapatkan : posisi berdiri lebih meningkatkan kenyamanan dibandingkan berbaring; duduk lebih meningkatkan kenyamanan dibandingkan berbaring, pada pembukaan serviks kurang dari $7 \mathrm{~cm}$; posisi tegak duduk, berdiri,atau berjalan menurunkan rasa nyeri dan meningkatkan kepuasan ibu; posisi tegak tidak memperpanjang masa persalinan dan tidak menyebabkan cidera pada ibu kala I persalinan ${ }^{13}$.

Posisi berbaring mirng adalah Arah posisi ibu tergantung pada letak ubun - ubun bayi.Jika berada di kiri, maka ibu anjurkan mengambil posisi miring ke kiri sehingga bayi diharapkan bisa berputar, demikian pula sebaliknya.Posisi ini mengharuskan ibu berbaring ke kiri atau ke kanan.Salah satu kakinya di angkat, sedangkan kaki lainya dalam keadaan lurus posisi yang sering disebut posisi lateral ini, umumnya dilakukan bila posisi kepala bayi belum tepat ${ }^{4}$.

Menurut Candra (2012) Ibu berbaring posisi sim, miring ke kiri atau ke kanan sesuai dengan anjuran dokter atau bidan. Kemudian pada saat poses persalinan, ibu hamil mengambil posisi dengan satu kaki diangkat kearah perut dan tangan sisi yang sama diletakkan pada lipatan antara lutut dan paha untuk mendekati dinding perut. Kelemahan posisi ini menyulitkan memonitor proses keluarnya kepala bayi dari dasar panggul dan demikian posisi miring saat bersalin dapat mempermudah turunnya kepala ke dasar panggul, meringankan pada saat kontraksi, tidak melelahkan, mempersingkat proses persalinan dan memperlancar sirkulasi peredaran darah ibu ke plasenta sehingga suplay oksigen bayi lebih maksimal ${ }^{14}$.

Posisi miring kiri berpengaruh terhadap kemajuan persalinan kala I karena dapat membantu mengarahkan kepala bayi ke posisi optimal selama kala I sehingga membuat ibu merasa lebih nyaman karena proses pembukaan terjadi secara perlahan (Werdinigsih, 2013).

Dengan posisi miring kiri kemajuan persalinan bisa berlangsung secara normal yaitu kala I (Primigravida) berlangsung 1 jam untuk setiap pembukaan $1^{15}$.

Posisi yang dirasakan paling nyaman oleh ibu adalah hal yang terbaik. Namum untuk membantu proses kemajuan persalinan kala I fase aktif bidan (petugas) akan meminta ibu mengubah posisi agar persalinan berjalan lancar, tetapi atas dasar dan kemauan ibu tanpa ada keterpaksaan. Sedangkan keunggulan posisi miring kiri terhadap proses kemajuan persalinan, peredaran darah balik ibu bisa mengalir lancar. Pengiriman oksigen dalam darah dari ibu ke janin melalui plasenta juga tidak terganggu karena tidak terlalu menekan vena cava inferior. Posisi melahirkan ini juga sangat cocok bagi ibu yang merasa nyeri di punggung atau kelelahan karena mencoba posisi yang lain. 
Tetapi posisi miring kiri proses pembukaan servik akan berlangsung secara perlahan-lahan, sehingga proses kemajuan persalinan berjalan lambat (Warna Dkk, 2014).

Beberapa ibu bersalin merasa bahwa berbaring miring ke kiri membuat mereka lebih nyaman dan efektif untuk mengatur nafas diantara kontraksi. Posisi berbaring ke kiri memudahkan ibu untuk beristirahat diantara kontraksi jika ia mengalami kelelahan. Namun pada posisi miring, dorongan untuk mengumpulkan tenaga pada saat menjelang persalinan lebih lemah karena janin tidak dapat meluncur secara berayun ke jalan lahir sehingga proses pembukaan dalam kemajuan persalinan lebih lambat. Umumnya kemajuan persalinan bergantung pada interaksi dari 3 variabel yaitu tenaga, jalan lahir dan janin.Selain dari 3 hal tersebut, riset menunjukkan bahwa posisi ibu dapat membantu mempercepat kemajuan persalinan ${ }^{18}$.

Sedangkan pada posisi miring dorongan untuk mengumpulkan tenaga pada saat menjelang persalinan lebih lemah karena janin tidak dapat meluncur secara berayun ke jalan lahir sehingga proses pembukaan dalam kemajuan persalinan lebih lambat. Berdasarkan teori diatas, penulis beropini bahwa adanya persalinan kala I fase aktif memanjang dapat meningkatkan resiko terjadinya komplikasi pada ibu dan bayi baik selama atau setelah persalinan ${ }^{16}$.

Pada penelitian Ariastuti dkk (2011), yang berjudul "Hubungan Antara Posisi Miring Kiri Dengan Proses Mempercepat Penurunan Kepala Janin Pada Proses Persalinan Di Bpm Ny. M Slerok Kota Tegal", terdapat 24 responden dengan menggunakan metode chi square, dan dari hasil penelitian ini menunjukan bahwa hasil uji fisher exact diperoleh Nilai $X 2$ Hitung $=1,263$ dan Nilai X 2 Tabel = 3,481 , jadi X 2 Hitung lebih kecil dari X 2 Tabel. Dan dari hasil uji fisher exact diperoleh nilai $\rho=0,544$ (nilai probabilitas ( $)>\alpha(0,05))$. Dengan demikian Ho diterima yang artinya tidak signifikan, sehingga tidak ada Hubungan Antara Posisi Miring Kiri dengan Proses Mempercepat Penurunan Kepala Janin

Pada penelitian Nilasari dkk (2013), yang berjudul "Perbedaan Lama Persalinan Kala I Fase Aktif Antara Posisi persalinan merangkak dan Miring pada Primigravida di Ruang Bersalin RS DKT Kota Kediri”, terdapat 38 responden menunjukkan bahwa sebagian besar (21 atau 55,26\%) ibu bersalin dengan posisi persalinan merangkak mengalami persalinan yang tidak memanjang, sedangkan hampir setengahnya (10 atau 36,84\%) ibu bersalin dengan posisi persalinan miring mengalami persalinan yang memanjang di Ruang Bersalin Rumah Sakit DKTI Kediri Kota Kediri. Setelah dilakukan uji SPSS dengan $\alpha$ kurang dari 0,005 maka pada penelitian ini diperoleh hasil bahwa $\alpha$ sebesar 0,026.Hal ini menunjukkan bahwa ada perbedaan lama persalinan kala I fase aktif dengan posisi persalinan merangkak dan miring di RS DKT Kota Kediri ${ }^{17}$.

\section{METODE PENELITIAN}

Jenis penelitian yang digunakan dalam penelitian ini adalah studi literatur. Pada awal penelitian, terlebih dahulu penulis menentukan isu penelitian yang akan dikaji, kemudian penulis mencari berbagai referensi sebagai bahan studi literatur. Mulai dari mencari jurnal, artikel, dan tinjauan pustaka secara elektronik di www.google.co.id, ttp://scholar.google.co.id/ dan https://books.google.co.id dengan menggunakan kata kunci "Efektifitas 
Upright position dan SIM position terhadap lamanya persalinan kala I fase aktif", "Pengaruh Upright positon terhadap lamanya kala I fase aktif", "Pengaruh SIM position terhadap lamanya persalinan kala I fase aktif", "standing position", dan "SIM position". Selain itu, penulis juga mencari referensi secara manual dengan mengunjungi perpustakaan Stikes Abdurahman Palembang dari tanggal 27 Februari 2020 sampai sekarang untuk memperluas wawasan dalam membuat studi literatur ini. Setelah mengumpulkan jurnal dan artikel dari berbagai sumber diatas, kemudian penulis melakukan analisis dan mengaitkannya dengan tinjauan pustaka yang kemudian dibuat kesimpulan. Untuk jurnal dan artikel berbahasa Inggris, penulis menerjemahkannya terlebih dahulu ke dalam bahasa Indonesia khususnya untuk kategori tujuan, metode penelitian: jenis penelitian, populasi sampel, instrumen penelitian, analisis data, dan hasil penelitian. Hasil terjemahan di analisis dan kemudian dibuat kesimpulan.

\section{HASIL DAN PEMBAHASAN}

\section{Efektifitas Posisi Berdiri (Upright) dengan Posisi Lain terhadap lamanya kala I fase aktif pada Primigravida}

Dalam penelitian yang dilakukan oleh Syaflindawati dkk (2015) Perbedaan rerata lama persalinan kala I fase aktif menurut posisi memperlihatkan bahwa rerata dan standar devasi pada posisi berbaring yaitu $263,68 \pm 39,47$ menit, sedangkan pada posisi upright yaitu $161,05 \pm 40,26$ menit terhadap lama persalinan kala I fase aktif pada ibu inpartu primigravida. Hasil uji $t$ Independent didapatkan nilai $p=0,000$ $(p<0,050)^{7}$.
Penelitian yang dilakukan oleh Astuti dkk (2013) Pada ibu primigravida kelompok intervensi, hasil observasi terhadap lama persalinan kala I dengan jam, rata-rata menunjukkan lama kala I adalah 7,22 jam dengan standar deviasi 2,028, sedangkan ibu pada kelompok kontrol rata-rata lama kala I adalah 14,66 jam dengan standar deviasi 3,534. Hasil penelitian sesuai dengan tujuan penelitian dan hipotesis kerja gagal ditolak lamanya kala I persalinan ibu primigravida yang mendapat posisi Upright lebih cepat dsari pada ibu primigravida yang tanpa posisi Upright ( $\mathrm{p}$ value 0,$000 ; \alpha 5 \%)^{19}$.

Penelitian yang dilakukan oleh Zainiyah (2015) diketahui bahwa posisi persalinan dengan miring kiri sebagian besar ibu bersalin mengalami kemajuan persalinan secara normal yaitu ibu bersalin $(56,25 \%)$, sedangkan posisi bersalin yang berdiri hampir seluruhnya ibu bersalin mengalami kemajuan persalinan secara cepat yaitu 14 ibu bersalin $(87,5 \%)$. setelah dilakukan uji statistic Maan whitney, didapatkan hasil $\mathrm{P}$ Value $(0,01)<\alpha(0,05)$ sehingga $\mathrm{Ha}$ diterima. Hal ini menunjukkan bahwa ada perbedaan kemajuan persalinan kala I fase aktif pada ibu bersalin yang diberikan posisi miring kiri dan posisi berdiri.

Pada penelitian Sri (2013) dilakukan analisis data dengan menggunakan independent samples $t$ test diperoleh $\mathrm{p}=$ 0,404 artinya tidak ada perbedaan lamanya persalinan kala I fase aktif pada primigravida antara upright position dengan recumbent position, meskipun nilai p \& gt : 0,05 , terdapat perbedaan rata-rata lamanya persalinan kala I fase aktif pada primigravida antara upright position dan recumbent position yaitu 16 menit, kesimpulan dalam penelitian ini adalah persalinan kala I fase aktif pada primigravida yang melakukan upright 
CENDEKIA MEDIKA

p-ISSN: 2503-1392

e-ISSN: 2620-5424

position lebih cepat dibandingkan dengan recumbent position ${ }^{20}$.

Berdasarkan hasil penelitian diatas dapat disimpulkan bahwa posisi yang paling tepat dan efektif untuk ibu inpartu kala I fase aktif pada primigravida yaitu posisi berdiri (Upright), untuk mempercepat proses persalinan ibu.

Menurut penulis Posisi berdiri tegak membuat ibu lebih leluasa bergerak dan mengalihkan perhatian saat mengalami kontrasi. Selain itu gerakan-gerakan bisa membantu posisi bayi mendekati jalan lahir. Posisi tegak pada proses persalinan kala I diasosiasikan dapat memberikan keuntungan pada ibu maupun bayi, karena dapat memberikan relaksasi dan memberikan sedikit tekanan pada sirkulasi darah sehingga memberikan suplai oksigen pada bayi, selain itu posisi tegak juga dapat mempercepat penurunan kepala karena adanya gaya gravitasi bumi sehingga memperpendek waktu persalinan kala I.

\section{Efektifitas Posisi Miring (SIM) dengan Posisi Lain terhadap Lamanya Kala I Fase Aktif Pada Primigravida.}

Penelitian yang dilakukan oleh Nilasari dkk (2013) bahwa sebagian besar dari 13 responden yang diberi posisi jongkok didapatkan seluruh responden mengalami percepatan kemajuan persalinan kala I fase aktif $\leq 6$ jam yaitu rata-rata 2-3 jam, sedangkan seluruh responden yang diberi posisi miring kiri, lama proses kemajuan persalinan kala I fase aktif berlangsung selama > 6 jam yaitu rata-rata 7-8 jam. Hasil analisis menggunakan t-test independen didapat nilai $\rho=0,000<\alpha=$ 0,05, maka H0 ditolak dan H1 diterima artinya posisi jongkok lebih efektif terhadap percepatan kemajuan persalinan kala I fase aktif pada ibu primipara dibandingkan dengan posisi miring kiri ${ }^{17}$.

Pada penelitian Ariastuti dkk (2014) terdapat 24 ibu yang melahikan menunjukkan bahwa sebagian besar lama kala I yaitu $\leq 6$ jam sebanyak 19 responden $(79,2 \%)$, dan > 6 jam sebanyak 5 responden $(20,8 \%)^{21}$.

Pada penelitan Lestari dkk (2019) hasil penelitian lainnya dari 8 responden didapatkan 4 responden yang di beri perlakuan posisi miring didapatkan 1 responden yang kemajuannya $>2$ jam dan 3 responden responden lainnya kemajuan persalinannya selama 2 jam. Sedangkan 4 responden yang di beri posisi setengah duduk didapatkan 1 responden yang kemajuannya $>2$ jam dan 3 responden responden lainnya kemajuan persalinannya selama 2 jam $^{22}$.

Berbeda dengan penelitian Syaidah dkk (2010), Posisi miring ke arah ubun-ubun kecil bermanfaat terhadap percepatan lama fase aktif kala I persalinan. Dari hasil penelitian didapatkan sebanyak 3 responden mengalami percepatan waktu fase aktif kala I, sedangkan 2 diantaranya mengalami perlambatan dan konstan ${ }^{23}$.

Berdasarkan hasil penelitian diatas bahwa posisi miring kurang efektif terhadap percepatan persalinan kala I fase aktif.

Menurut penulis karena tidak terlalu menekan, proses pembukaan akan berlangsung secara perlahan-lahan. Beberapa ibu bersalin merasa bahwa berbaring miring ke kiri membuat mereka lebih nyaman dan efektif untuk mengatur nafas diantara kontraksi. Posisi berbaring ke kiri memudahkan ibu untuk beristirahat diantara kontraksi jika ia mengalami kelelahan. Namun pada posisi miring, dorongan untuk mengumpulkan tenaga 
CENDEKIA MEDIKA

p-ISSN: 2503-1392

e-ISSN: 2620-5424 pada saat menjelang persalinan lebih lemah karena janin tidak dapat meluncur secara berayun ke jalan lahir sehingga proses pembukaan dalam kemajuan persalinan lebih lambat.

\section{SARAN}

Diharapkan untuk penelitian selanjutnya dapat melakukan pengembangan penelitian efektifitas poisisi berdiri terhadap percepatan proses persalinan pada kala I fase aktif dengan metode lain

\section{DAFTAR PUSTAKA}

1. Suhartika. (2018). KEBIDANAN Teori dan Asuhan. Jakarta: Buku Kedokteran EGC.

2. Prawihardjo, S. (2011). Ilmu Kebidanan Sarwono

Prawihardjo.Jakarta : Bina Pustaka Sarwono Prawihardjo.

3. Rohani, Saswita, R. dan Marisah. (2011). Asuhan Kebidanan pada Masa Persalinan. Jakarta: Selemba Medika.

4. Sulistyawati, A. dan Nugraheny, E. (2010). Asuhan Kebidanan Pada Ibu Bersalin. Jakarta: Selemba Medika.

5. Bobak, M. Lowdermilk, dan Jensen, M. D. (2009). Buku Ajar keperawatan Matternitas. Jakarta: EGC

6. Wigand dan Leigh. (2012). Position in labour. NHS Foundation Trust, Obstetrics and Gynecology Depetement

7. Syaflindawati, Rahmatina, Herman, dan Ilyas, J. (2015). Pengaruh Upright Position Terhadap lamanya Kala I Fase Aktif pada Primigravida. Jurnal Kesehatan Andalas. Vol 4(3).

8. Lawrence, A. Lewis, L. dan Hofmeyr, G. (2009). Journal maternal position and mobility duringfirst stage labour.s
9. Sherwood L. (2012). Fisiologi manusia dari sel-ke sel. Jakarta: EGC.

10. Simkin. (2005). Buku Saku Persalinan. Jakarta: Buku Kedokteran EGC.

11. Brenda, L. (2006). Pain Relief Techniques Labor. http://pregnancychilbirth.suite101.co m/orticle.cfan/. Di akses pada tanggal 23 Februari 2010.

12. Titi Astuti , Mashaurani Yamin (2013). Pengaruh Posisi Tegak (Upright) Terhadap Rasa Nyeri Dan Lamanya Kala I Persalinan Ibu Primipara. Jurnal Keperawatan, Volume Ix, No. 1, April 2013

13. Simkin, B. dan Bolding, A. (2004). Buku Ajar Konsep Kebidanan. Jakarta: EGC.

14. Candra. A. (2012). Keunggulan dan Kelemahan Beberapa Posisi Saat Bersalin. https://tekno.kompas.com. Di akses pada tanggal 26 februari 2020.

15. Setyorini. (2013). Belajar Tentang Persalinan. Yogyakarta : Graha Ilmu.

16. Sylvia. (2003). Ilmu Kesehatan Masyarakat Prinsip-Prinsip Dasar. Jakarta : Rineke Cipta.

17. Nilasari, N. Kharisma, B. Putri, A. dan Andriyanti, A. (2013). Perbedaan Lama Persalinan Kala I Fase Aktif Antara Posisi persalinan merangkak dan Miring pada Primigravida di Ruang Bersalin RS DKT Kota Kediri.

18. Bernard.Bonnie.2004. Resiliency: What We Have Learned. San Fransisco: WestEd.

19. Astuti, T. dan Yamin, M. (2013). Pengaruh Posisi Tegak (Upright) Terhadap Rasa Nyeri Dan Lamanya Kala I Persalinan Ibu Primipara. Jurnal Keperawatan, Vol. 9, No, 1.

20. Sri, W. (2013). Perbedaan Antara Upright Position dengan Recumben 
Position Terhadap Lamanya Persalinan Kala I Fase Aktif pada Primigravida di Wilayah Kecamatan Blimbing Kota Malang.

21. Ariastuti, N.D. Sucipto, E. dan Andari, I.D. (2014). Hubungan Antara Posisi Miring dengan Proses Mempercepat Penurunan Kepala Janin Pada Proses Persalinan di BPM NY.M Slerok kota Tegal.

22. Lestari, Y. D. dan Hasanah, S. (2019). Efektifitas pemberian posisi miring kiri dan setengah duduk terhadap kemajuan persalinan kala satu fase aktif dilatasi maksimal pada primigravida. Jurnal Keperawatan Profesional (JKP). Vol 7(1).

23. Syaidah, E. dan Yuliastanti, T. (2011). Analisis Posisi Ibu Bersalin Miring Ke Arah Ubun-Ubun Kecil Terhadap Lama Fase Aktif Kala I Di Puskesmas Sukodono Sragen. Jurnal Kebidanan, Vol. 3(2). 